\title{
Breastfeeding is associated with children's dietary diversity in Brazil
}

\author{
Amamentação está associada à diversidade alimentar infantil \\ no Brasil
}

Gisele Ane Bortolini (https://orcid.org/0000-0002-7830-9134) ${ }^{1}$

Elsa Regina Justo Giugliani (http://orcid.org/0000-0001-6569-6473) ${ }^{2}$

Muriel Bauermann Gubert (https://orcid.org/0000-0002-0103-4187) ${ }^{1}$

Leonor Maria Pacheco Santos (http://orcid.org/0000-0002-6739-6260) ${ }^{3}$

${ }^{1}$ Departamento de Nutrição, Universidade de Brasília. Campus Universitário Darcy Ribeiro, Asa Norte. 70910900 Brasília DF Brasil. murielgubert@gmail.com ${ }^{2}$ Departamento de Pediatria, Faculdade de Medicina, Universidade Federal do Rio Grande do Sul. Porto Alegre RS Brasil.

${ }^{3}$ Departamento de Saúde Coletiva, Universidade de Brasília. Brasília DF Brasil.
Abstract The aim of this study was to describe food consumption patterns in Brazilian children aged 6-24 months and to assess differences between breastfed children who do not consume non -human milks, breastfed children who consume non-human milks, and non-breastfed children. This study used data from the Brazilian National Demographic and Health Survey (2006). The food consumption patterns of 1,455 children were assessed using a food frequency questionnaire. One indicator adopted in this study was the healthy diverse diet. The association between breastfeeding and food consumption was tested using multivariate Poisson regression. At the interview, $15.8 \%$ of the children were breastfed without consuming non-human milk, 30.7\% consumed breast milk in conjunction with non-human milk, and 53\% were not breastfed anymore. Over half consumed the recommended foods, $78 \%$ consumed foods rich in sugar, fat, and salt, and only $3.4 \%$ were on a healthy diverse diet. The breastfed children who did not consume non-human milks were almost five times more likely to be on a healthy diverse diet and were 19\% less likely to consume foods rich in sugar, fat, and salt than the breastfed children who also consumed non-human milks and the non-breastfed children.

Key words Food consumption, Breastfeeding, Non-human milk, Healthy diet.
Resumo O objetivo foi descrever o padrão de consumo alimentar em crianças brasileiras entre 6 e 24 meses e verificar as diferenças entre crianças em aleitamento materno (AM) que consomem ou não outros tipos de leites não-humano (LNH), e aquelas não amamentadas (NAM). Foram usados dados da Pesquisa Nacional de Demografia e Saúde (2006). O consumo alimentar de 1455 crianças foi avaliado usando um questionário de frequência alimentar. Avaliou-se a presença de dieta saudável e diversificada. A associação entre AM e o consumo alimentar foi testado pela regressão de Poisson. Na entrevista, 15,8\% das crianças estavam em AM sem consumo de LNH, 30,7\% estavam em AM com consumo de LNH e 53\% não estavam em AM. Mais da metade consumiam os alimentos recomendados, $78 \%$ consumiam alimentos ricos em açúcar, gordura e sal, e apenas 3,4\% estavam em uma dieta saudável e diversificada. As crianças em AM que não consumiam LNH tinham quase cinco vezes mais chances de ter uma dieta saudável e diversificada e tinham $19 \%$ menos chance de consumir alimentos ricos em açúcar, gordura e sal, comparadas àquelas que também consumiam LNH e àquelas que não estavam em AM.

Palavras-chave Consumo alimentar, Aleitamento materno, Leite não-humano, Dieta saudável. 


\section{Introduction}

Breastfeeding and healthy complementary feeding have positive effects on the growth and development of children and also help decrease the risk of morbidity and mortality in childhood and adulthood $^{1,2}$. The World Health Organization and the Brazilian Ministry of Health recommends exclusive breastfeeding in the first six months of life and complementary feeding with healthy foods from then until 2 years of age or more ${ }^{3,4}$.

In Brazil $41 \%$ of the children up to 6 months of age were exclusively breastfed and the median duration of breastfeeding is 11.2 months ${ }^{5}$. There is an early introduction of water $(60,4 \%)$, teas $(16,5 \%)$, and milks other than breast milk $(48,8 \%)^{6}$, especially unmodified cow's milk ${ }^{7}$ before 6 months of age, as well as a high consumption (up to $35 \%$ ) of unhealthy foods like soda, candies and snacks by children aged 6-59 months ${ }^{8}$.

Previous studies showed an association between breastfeeding and the adequacy of complementary feeding ${ }^{9,10}$. However, while a recent Brazilian study showed a positive association between breastfeeding and greater consumption of vegetables, it failed to find any association between duration of breastfeeding and consumption of fruits ${ }^{11}$. These findings suggest that strategies to improve the dietary habits of Brazilian children are needed. In order to do so, detailed information about the food consumption patterns of specific age groups must be gathered, as well as the factors that help or hinder the observance of healthier dietary practices.

The objective of this study was to describe food consumption patterns in Brazilian children aged 6-24 months and to assess differences related to the children's breastfeeding status.

\section{Method}

This study used secondary data from the 2006 Brazilian National Demographic and Health Survey (DHS). The Brazilian DHS investigated women between 15 and 49 years old and their children aged 5 or younger. The survey used a complex sampling procedure, and represents the five Brazilian macro-regions and urban and rural areas. A total of 14,617 households were selected, and 15,575 women and 4,957 children aged 5 or younger were researched. The sampling and data collection procedures are described in detail elsewhere ${ }^{12}$.
Data were obtained by interviewing women using a structured questionnaire. One questionnaire module covered breastfeeding practices. Another questionnaire module was focused on the children's weekly consumption frequency of: cereals (rice, pasta), beans, tubers (potatoes, manioc, yam, pumpkins), leafy greens, vegetables (tomatoes, carrots, beets, eggplants, chayote, zucchini), fruit, yogurt, bread, beef, pork, chicken, fish, natural/fresh fruit juice, fried foods, candies, cookies, processed snacks, soft drinks, and artificial fruit juices. The following categories were used to describe food intake by children aged 6-24 months: a) no intake in the seven days before the interview; b) intake on 1-3 days in the week before the interview; (c) intake on 4-6 days in the week before the interview; (d) daily intake in the week before the interview.

The quality of the children's diet was assessed using the criteria presented in Table 1. We analyzed four groups of food based in the Brazilian official recommendations for children under 2 years of age $e^{4}$. They recommend a daily consumption of: fruits/vegetables, meat, beans, and cereals/tubers and recommend to avoid the consumption of foods rich in salt, fat and sugar. As frequency criteria for the healthy foods we considered adequate when their consumption occurred in the most days of the week (at least 4 times a week). For not recommended foods it was considered adequate when the consumption did not occur in the last week. For healthy diverse diet we could not use the WHO indicator ${ }^{13}$ because the Brazilian DHS did not collect all variables necessary. The WHO indicator was adapted and a healthy diverse diet was defined as the consumption of recommended food groups (fruit/ vegetables, meat, beans, and cereals/tubers) at least four times a week, plus no intake of foods rich in sugar, fat, and salt in the week before the interview, except for cookies, as over $90 \%$ of the children had consumed these the previous week. All the components of these criteria were binary (yes/no).

Children were grouped into three categories according to their current breastfeeding status: a) breastfed without consuming non-human milks, breastfed and consuming non-human milks, and non-breastfed. Non-human milks include animal (cow or goat) milk, powdered milk, formula, and soya or rice milk.

All the analyses were performed using Stata software, version 11.0, and considered the complex design of the sample. The inclusion criteria were children aged between 6 and 24 months, 
Table 1. Criteria used to assess food consumption in Brazilian children aged 6-24 months (Brazilian National Demographic and Health Survey of Women and Children, 2006)

\begin{tabular}{ll}
\hline \multicolumn{1}{c}{ Foods } & \multicolumn{1}{c}{ Minimum Recommended Frequency } \\
\hline Fruit/Vegetables & Intake of fruit, vegetables, or leafy greens at least four times a week \\
Meat & Intake of chicken, beef, or pork at least four times a week \\
Beans & Intake of beans at least four times a week \\
Cereals/Tubers & Intake of cereals or tubers at least four times a week \\
Foods rich in sugar, fat, and salt & No intake of candies, soft drinks, processed snacks, or fried foods in the \\
& previous week \\
Healthy diverse diet & $\begin{array}{l}\text { Intake of fruit, vegetables, or leafy greens at least four times a week }+ \text { intake } \\
\text { of meat at least four times a week + intake of fish, liver, or egg at least once a } \\
\end{array}$ \\
& week + intake of beans at least four times a week + intake of cereals or tubers \\
& at least four times a week + no intake of candies, soft drinks, processed \\
& snacks, or fried foods in the previous week \\
\hline
\end{tabular}

${ }^{*}$ Minimum diet frequency adopted from WHO recommendations

living with their mothers and completed food consumption questionnaires. The final database comprised data from 1,455 children. When the independent variable was used (breastfeeding status), sample size was reduced to 1,379 children, as there were no data available on the consumption of breast milk for 44 children and of other milks for 76 .

Bivariate Poisson regression was used to assess the association between the independent variable and the dependent variables (consumption of different food groups). Adjusted analyses were performed using Poisson regression, adjusted for region, area of residence (urban or rural), number of residents in household, mother's education and socioeconomic levels, household food insecurity status, mother's and child's age.

Household food insecurity was assessed using the Brazilian Food Insecurity Scale (Escala Brasileira de Insegurança Alimentar, EBIA). This tool consists of 14 questions ranging from concern about food shortage to children going a whole day without eating. The score is the sum of affirmative answers to the items and households were classified in: secure (score $=0)$, slightly insecure ( score $=1$ to 5 ), moderately insecure ( score $=6$ to 9 ), and severely insecure (score $=10$ to 14$)^{14}$.

Socioeconomic level was determined according to the Brazilian Economic Classification Criteria, that allocates the household into an economic grade or stratum from $\mathrm{A}$ to $\mathrm{E}$. For this study, they were grouped in $\mathrm{A} / \mathrm{B}, \mathrm{C}$, and $\mathrm{D} / \mathrm{E}^{15}$.

We used secondary data from a public database. The original study protocol was approved by the Research Ethics Committee of São Paulo State Department of Health, Brazil ${ }^{12}$.

\section{Results}

Over $80 \%$ of the children lived in urban areas. Nearly $50 \%$ of the households were from socioeconomic classes D and E. Other characteristics of the sample, as well as information on breastfeeding status, are presented in Table 2. Of all the children aged 6-24 months, $15.8 \%$ were breastfed and did not consume non-human milk, $30.7 \%$ consumed breast milk in conjunction with non-human milk, and 53\% were no longer breastfed.

Table 3 shows the weekly frequency of consumption of the different foods by the children aged 6-24 months. Most of them consumed beans $(62.8 \%)$ and cereals (69.9\%) every day, and almost half (45.4\%) consumed fruit every day. However, a low intake of leafy greens, vegetables, and meat was observed, and a high percentage of children consumed candies $(66.0 \%)$, processed snacks (41.6\%), soft drinks (58.0\%), and cookies $(88.9 \%)$ more than once a week.

Over half of the Brazilian children assessed met the criteria for the minimum recommended frequency of consumption of fruit/vegetables $(65.1 \%)$, beans $(70.3 \%)$ and cereals/tubers $(82.3 \%)$, except for meat $(40.0 \%)$. However, $87.6 \%$ consumed non-recommended foods rich in sugar, fat, and salt. Only $3.4 \%$ of the children consumed all the foods with the minimum recommended frequency and did not consume any foods rich in sugar, fat, or salt (definition of healthy diverse diet in this study) (Table 4).

Table 5 shows the results of the crude and adjusted analyses conducted to test the associations between breastfeeding status and the consump- 


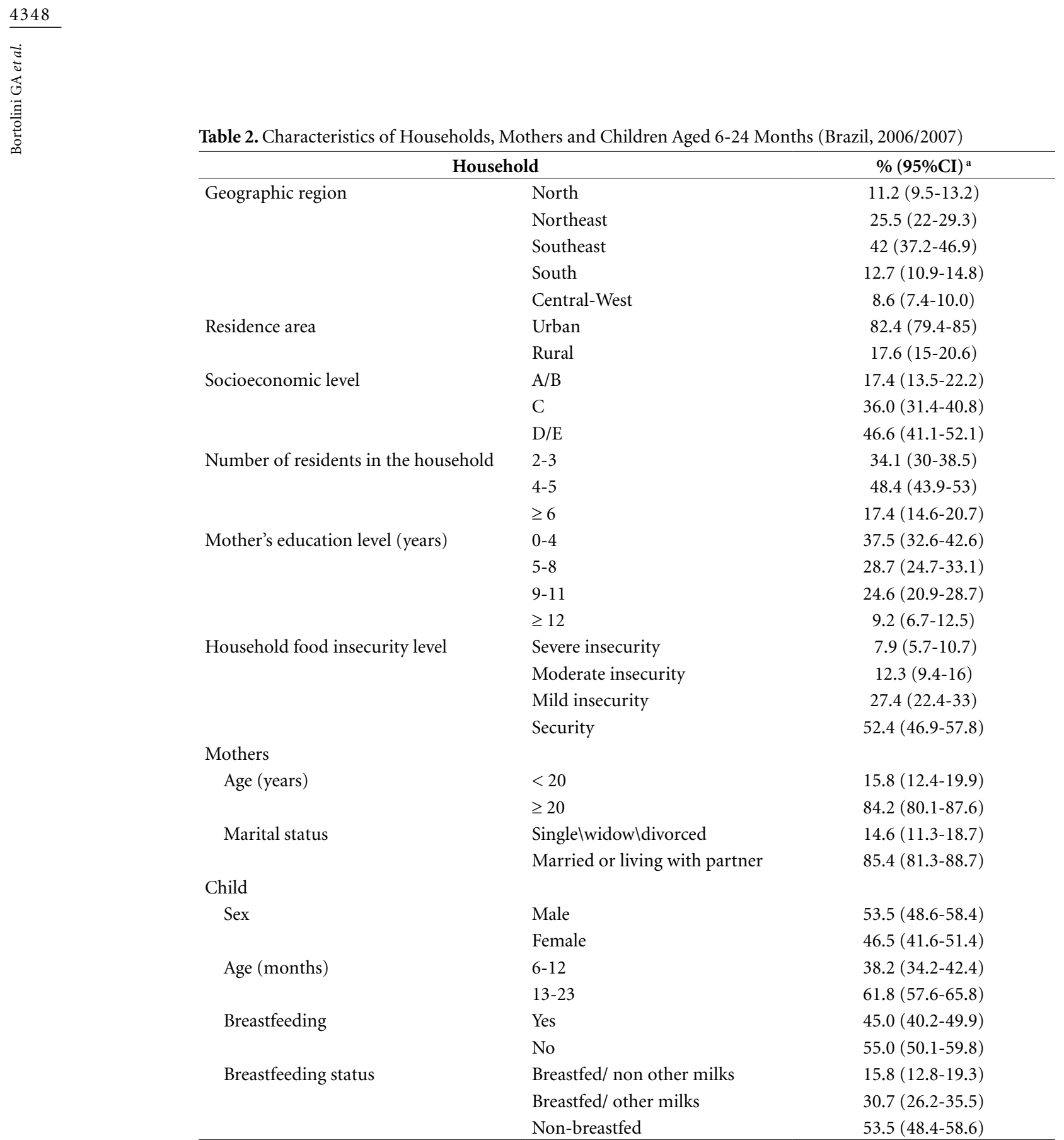

95\%CI $=95 \%$ confidence interval. ${ }^{\text {a }}$ Expanded sample.

tion of other foods. Almost 10\% of the breastfed children who did not consume non-human milks presented a healthy diverse diet. After adjustment for factors that may influence food consumption, these children showed a 4.6 times higher chance of being on a healthy diverse diet than the children being fed non-human milks in addition to breast milk and the children who were not breastfed. These children were also 19\% less likely to consume foods rich in sugar, fat, and salt.

\section{Discussion}

The results of this study provide evidence that the diet of Brazilian children aged 6-24 months is primarily based on the consumption of beans and cereals, especially rice. Although the DHS is not comparable with the National Dietary Survey data, collected as part of the 2008-2009 Household Budget Survey (POF), this same cultural pattern was reported for Brazilian adolescents, 
Table 3. Weekly food consumption in children aged 6-24 months (Brazil, 2006/2007).

\begin{tabular}{lcccc}
\hline & \multicolumn{4}{c}{ Weekly frequency of consumption $\mathbf{~ ( \% ) ~}$} \\
\cline { 2 - 4 } & No intake & $\mathbf{1 - 3}$ times & $\mathbf{4 - 6}$ times & Every day \\
\hline Beans & 11.5 & 18.3 & 7.5 & 62.8 \\
Tubers & 25.2 & 45.5 & 10.2 & 19.1 \\
Cereals (rice and pasta) & 7.8 & 16.2 & 6.1 & 69.9 \\
Leafy greens & 59.4 & 26 & 4.3 & 10.4 \\
Vegetables & 25.1 & 37.3 & 12 & 25.6 \\
Fruit & 14.4 & 27.9 & 12.2 & 45.4 \\
Natural/fresh juice & 24.7 & 26.2 & 12.7 & 36.4 \\
Meat (beef or pork) & 25.8 & 44.2 & 11 & 19.1 \\
Chicken & 29.8 & 54.7 & 10.3 & 5.2 \\
Fish & 68.2 & 28.4 & 2.4 & 0.9 \\
Liver & 77.1 & 20.9 & 1.3 & 0.8 \\
Egg & 50.6 & 39.3 & 7.2 & 2.8 \\
Bread & 20 & 33.0 & 6.5 & 40.4 \\
Yogurt & 29.0 & 33.8 & 14.3 & 22.9 \\
Fried foods & 66.1 & 26.3 & 3.8 & 3.9 \\
Candies & 44.0 & 34.3 & 8.3 & 13.5 \\
Cookies & 11.1 & 28.0 & 18.3 & 42.7 \\
Processed snacks & 58.4 & 28.5 & 6.2 & 6.9 \\
Soft drinks or artificial fruit juices & 42.0 & 33.0 & 9.6 & 15.5 \\
\hline Exanded & & & & \\
\hline
\end{tabular}

${ }^{\mathrm{a}}$ Expanded sample.

Table 4. Weekly frequency of consumption of different food groups by children aged 6-24 months (Brazil, 2006/2007)

\begin{tabular}{|c|c|c|}
\hline Food group & Criteria & $\%(95 \% C I)^{a}$ \\
\hline Fruit/vegetables & Intake at least four times a week. & $65.1(59.6-70.2)$ \\
\hline Meat & Intake at least four times a week. & $40.0(35.4-44.9)$ \\
\hline Beans & Intake at least four times a week. & $70.3(66.2-74)$ \\
\hline Cereals/tubers & Intake at least four times a week. & $82.3(78.9-85.3)$ \\
\hline $\begin{array}{l}\text { No intake of foods rich } \\
\text { in sugar, fat, and salt }\end{array}$ & $\begin{array}{l}\text { No intake of candies, soft drinks, processed snacks, or fried foods in } \\
\text { the previous week. }\end{array}$ & $22.4(19.0-26.3)$ \\
\hline Healthy diverse diet & $\begin{array}{l}\text { Intake of fruit, vegetables, or leafy greens at least four times a week } \\
+ \text { intake of chicken, beef, or pork at least four times a week }+ \text { intake } \\
\text { of fish, liver or egg at least once a week }+ \text { intake of beans at least } \\
\text { four times a week }+ \text { intake of cereals or tubers at least four time a } \\
\text { week }+ \text { no intake of candies, soft drinks, processed snacks, or fried } \\
\text { foods in the previous week. }\end{array}$ & $3.4(1.9-5.9)$ \\
\hline
\end{tabular}

${ }^{a}$ Expanded sample.

adults and elderly in that survey ${ }^{16}$. This result indicates that the children's food consumption may be mediated by the family members ${ }^{17}$.

Conversely, the consumption of leafy greens, vegetables and meat was low, and the frequency of consumption of foods rich in sugar, fat, and salt, such as cookies, candies, processed snacks, and soft drinks was high. Considering the Brazilian government's latest recommendations about what constitutes a healthy diet for children younger than 2 years of age, the dietary habits observed in this study were far from ideal ${ }^{4}$. Another study of children of 6-11.9 months of age between 1998 and 2008 showed that there was a downward trend over this period in the consumption of iron-rich foods and a worsening of complementary feeding practices ${ }^{18}$.

With regard to breastfeeding status, approximately half of the children aged 6-24 months were breastfed, but breast milk was the only source of 
Table 5. Food consumption in Brazilian children aged 6-24 months according to breastfeeding status (Brazil, 2006/2007)

\begin{tabular}{llccc}
\hline & Breastfeeding category & $\begin{array}{c}\text { \% } \\
\text { intake }\end{array}$ & $\begin{array}{c}\text { PR (95\%CI) } \\
\text { Crude Poisson }\end{array}$ & $\begin{array}{c}\text { PR (95\%CI) } \\
\text { Adjusted } \\
\text { Poisson }^{\text {b }}\end{array}$ \\
\hline Fruit/Vegetables $^{\mathrm{c}}$ & Breastfed/non-other milks & 58.3 & $0.85(0.69-1.05)$ & $0.89(0.70-1.14)$ \\
& Breastfed/ other milks & 64.9 & $0.95(0.79-1.13)$ & $1.00(0.82-1.22)$ \\
& Non-breastfed & 68.3 & 1 & 1 \\
Meat $^{c}$ & Breastfed/non-other milks & 36.2 & $0.85(0.61-1.19)$ & $1.00(0.76-1.31)$ \\
& Breastfed/ other milks & 36.3 & $0.85(0.65-1.12)$ & $1.15(0.88-1.49)$ \\
Beans $^{c}$ & Non-breastfed & 42.3 & 1 & 1 \\
& Breastfed/non-other milks & 64.4 & $0.84(0.72-0.98)$ & $0.96(0.82-1.11)$ \\
& Breastfed/ other milks & 64.5 & $0.84(0.73-0.96)$ & $0.95(0.84-1.07)$ \\
Cereals/Tubers $^{c}$ & Non-breastfed & 76.2 & 1 & 1 \\
& Breastfed/non-other milks & 75.2 & $0.86(0.76-0.98)$ & $0.92(0.82-1.04)$ \\
& Breastfed/ other milks & 80.6 & $0.92(0.85-1.00)$ & $1.01(0.94-1.10)$ \\
Foods rich in sugar, fat, and salt $^{\mathrm{d}}{ }^{\mathrm{c}}$ & Non-breastfed & 86.6 & 1 & 1 \\
& Breastfed/non-other milks & 60.4 & $0.71(0.58-0.87)$ & $0.81(0.68-0.97)$ \\
& Breastfed/ other milks & 76.2 & $0.90(0.81-0.99)$ & $0.99(0.90-1.09)$ \\
& Non-breastfed & 84.3 & 1 & 1 \\
Healthy diverse diet $^{\mathrm{e}}$ & Breastfed/non-other milks & 9.5 & $3.57(0.96-13.24)$ & $4.57(1.67-12.46)$ \\
& Breastfed/ other milks & 1.5 & $0.56(0.12-2.52)$ & $0.89(0.19-4.19)$ \\
& Non-breastfed & 2.7 & 1 & 1 \\
\hline
\end{tabular}

a Breastfeeding categories: Breastfed/ non-other milks: receiving only breast milk and not receiving any other milks; Breastfed/ other milks: receiving other milks in addition to breast milk; non-breastfed: receiving other milks only (and not receiving breast milk). Other milks include animal (cow or goat) milk, powder milk, artificial formula feeding, and soya or rice milk.

${ }^{\mathrm{b}}$ Analyses adjusted for child's age, mother's education level, household region and area, mother's age, number of residents in the household, food insecurity level, and socioeconomic level.

${ }^{c}$ least 4 times weekly.

${ }^{\mathrm{d}}$ No intake of candies or soft drinks or processed snacks or fried foods in the previous week.

${ }^{\mathrm{e}}$ Intake of fruit or vegetables or leafy greens at least 4 times weekly + intake of chicken or beef/pork at least 4 times weekly + intake of fish or liver or egg at least once weekly + intake of beans at least 4 times weekly + intake of cereals or tubers at least 4 times weekly + no intake of candies or soft drinks or processed snacks or fried foods in the previous week.

milk for only $15.8 \%$ of them. Breastfeeding indicators have progressed significantly in Brazil over the last few decades, especially as a result of public health policies designed to promote, protect, and support this practice ${ }^{19}$. However, the fact that unmodified cow's milk accounted for $75 \%$ of non-human milks is worrying ${ }^{8}$.

An alarming finding of the present study was the low prevalence of children on a healthy diverse diet, which is defined here according to the official Brazilian recommendations for this age group. More than half the children consumed healthy foods, but very few did not consume any unhealthy foods. A combination of both practices would be ideal. It is clear that in addition to stimulating the intake of healthy foods, such as fruit, vegetables, meat, beans, cereals, and tubers, it is also necessary to discourage the consumption of unhealthy foods, as the consumption of healthy foods does not seem to reduce the consumption of unhealthy foods. Recently, the Pan American Health Organization published a document designed to support Latin American countries in their public policymaking to help reduce children's exposure to the promotion and advertising of foods rich in fat, sugar, and salt, in an attempt to reduce the risks to children's health ${ }^{20}$.

A high frequency of consumption of foods rich in sugar, fat, and salt may predispose to overweight, a risk factor for other chronic diseases ${ }^{21}$. National statistics indicate that the prevalence of overweight in children aged 5 or younger is $7.4 \%$, rising to $33.5 \%$ in children aged 5 to 9 , and $50.1 \%$ in the adult population ${ }^{12,22}$. Overweight and obesity are a global public health concern that requires urgent measures. There is evidence 
to suggest that breastfeeding and healthy complementary feeding may decrease the chance of a child becoming overweight later in life ${ }^{23-26}$.

Taking into consideration the healthy dietary criteria adopted in the present study, we may conclude that generally speaking Brazilian children do not follow the official recommendations and consequently are not eating healthily. Most studies designed to assess the diversity of food consumption patterns in children focus only on the consumption of healthy foods and disregard the intake of unhealthy foods ${ }^{27-30}$. In this sense, the present study emphasizes the need to adopt a broader perspective when evaluating children's feeding practices as it has been demonstrated that the intake of different food groups (diverse diet) reduces the chances of malnutrition and nutritional deficiencies among children, whereas the intake of foods with a high energy density increases the chances of children becoming overweight $^{21,27,28,31}$.

A significant result of the present study was that the breastfed children who did not consume non-human milks were more likely to be on a healthy diverse diet, defined as a combination of the intake of healthy foods and no intake of foods rich in sugar, fat, and salt. This finding corroborates the results of a previous study conducted in Norway, in which 12-month-old breastfed children consumed fewer sugar-sweetened beverages and had less sugar added to their beverages than their non-breastfed counterparts ${ }^{32}$. Conversely, our results differ from those reported for Danish children, whose diet at 9 months of age was similar between breastfed and non-breastfed children, despite the later introduction of complementary foods in the former group. However, those investigators did not inquire whether the breastfed children were also receiving non-human milk, which may explain the different results obtained $^{33}$.

Two other Brazilian studies have looked at the relationship between breastfeeding duration and dietary habits later in life. One found that being breastfed up to 6 months reduced the risk of consumption of lipid-dense foods at 12 months old by $58 \%$ and sugar-dense foods by $67 \%{ }^{34}$. The other found that a longer duration of breastfeeding was positively associated with the consumption of vegetables in children aged 4-7 years; however, there was no association with consumption of fruits ${ }^{11}$.

One hypothesis to explain the association between longer breastfeeding and better feeding patterns later in childhood could be that the fam- ilies who follow the recommendation to maintain breastfeeding for up to 2 years or more, not offering non-human milk, are the same families that strive to incorporate other recommendations for a healthy diet, as reported in a previous study conducted in southern Brazil ${ }^{34}$. This has been observed in the United States, where the mothers who followed the recommendations of the American Academy of Pediatrics in relation to breastfeeding also tended to make better dietary choices for their children ${ }^{35}$.

Another hypothesis that has been suggested to explain the healthier diet of breastfed children is the fact that these children could be exposed to a larger variety of tastes through breast milk in early life than formula-fed children. Early exposure to different tastes present in the amniotic fluid during pregnancy and in breast milk during the first months of life could improve food acceptance during the introduction of complementary feeding ${ }^{36,37}$. The design of the present study does not allow this hypothesis to be confirmed or rejected, as we did not evaluate the breastfeeding status of the children at the time of the introduction of complementary foods.

It is important to note that the questionnaire used to assess food consumption did not provide information on the amounts ingested, but this fact cannot be considerate a limitation because even the WHO's indicator for dietary diversity does not use quantities, only the presence and the absence of certain foods in the child's diet.

Unfortunately, the data available at the Brazilian DHS did not allow the use of WHO's minimum dietary diversity indicator. This indicator is based on the consumption or four or more of the following food groups the day before: grains/ roots/tubers; legumes/nuts; milk/dairy products; flesh foods; eggs; vitamin A rich fruits and vegetables; and other fruits and vegetables ${ }^{13}$. This indicator was proposed in 2010, after completion of the 3rd edition of the Brazilian DHS, and therefore could not be used in the present analysis. Rather, we decided to use an indicator of healthy diverse diet consisting of a combination of intake of healthy foods at the recommended frequency, plus no intake of unhealthy foods, based on official Brazilian recommendations for the diet of children of up to 2 years of age ${ }^{4}$.

It is important to note that we used current breastfeeding status rather than total duration of breastfeeding, since this survey did not provide this information. As the probability of being currently breastfed declines with age, and the likelihood of eating a complex diet increases with age, 
it is reasonable to assume that a child's age mediates a probable relationship between current breastfeeding and diet complexity. This could explain why some associations in the unadjusted model lost their significance in the adjusted model, which included child's age. Also, using the current status method, recently weaned children were classified as not breastfed, even if breast milk was their predominant diet until very recently. Consequently, this study mainly compared the diet of breastfed (without or in conjunction with non-human milks) and non-breastfed children. Therefore, we can only conclude that breastfed children not receiving non-human-milk, regardless of age, have a healthier diet.

\section{Conclusion}

The results of this study show that food consumption in most Brazilian children aged 6-24 months is far from ideal among both breastfed and non-breastfed children. However, despite the low prevalence of children on a healthy diverse diet, breastfed children who did not consume non-human milks were more likely to be on a healthy diverse diet, as their consumption of foods rich in sugar, fat, and salt was lower than that of the children who consumed other types of milk. The low frequency of children on a healthy diverse diet found in this study underscores the need for actions aimed at promoting, protecting, and supporting both breastfeeding and healthy complementary feeding in breastfed and non-breastfed children.

\section{Collaborators}

The authors participated equally in the writing of this manuscript. 


\section{References}

1. Horta BL, Victora CG. Long-term effects of breastfeeding: a systematic review. Geneva: WHO; 2013.

2. Martin A, Bland RM, Connelly A, Reilly JJ. Impact of adherence to WHO infant feeding recommendations on later risk of obesity and non-communicable diseases: systematic review. Matern Child Nutr 2015;12(3):418-427.

3. Kramer MS, Kakuma R. Optimal duration of exclusive breastfeeding. Cochrane Database Syst Rev 2012;8:CD003517.

4. Brasil. Ministério da Saúde (MS). Dez passos para uma alimentação saudável: guia alimentar para menores de dois anos. Um guia para o profissional da saúde na atenção básica. Brasília: MS; 2010.

5. Venancio SI, Saldiva SR, Monteiro CA. Secular trends in breastfeeding in Brazil. Rev Saude Publica 2013;47(6):1205-1208.

6. Brasil. Ministério da Saúde (MS). Secretaria de Atenção à Saúde. Departamento de Ações Programáticas e Estratégicas. II Pesquisa de Prevalência de Aleitamento Materno nas Capitais Brasileiras e Distrito Federal. Brasília: MS; 2009.

7. Bortolini GA, Vitolo MR, Gubert MB, Santos LM Early cow's milk consumption among Brazilian children: results of a national survey. J Pediatr (Rio J) 2013;89(6):608-613.

8. Bortolini GA, Gubert MB, Santos LM. Food consumption in Brazilian children by 6 to 59 months of age. Cad Saude Publica 2012;28(9):1759-1771.

9. Scott JA, Chih TY, Oddy WH. Food variety at 2 years of age is related to duration of breastfeeding. Nutrients 2012;4(10):1464-1474.

10. Lauzon-Guillain B, Jones L, Oliveira A, Moschonis G, Betoko A, Lopes C, Moreira P, Manios Y, Papadopoulos NG, Emmett P, Charles MA. The influence of early feeding practices on fruit and vegetable intake among preschool children in 4 European birth cohorts. Am J Clin Nutr 2013;98(3):804-812.

11. Soldateli B, Vigo A, Giugliani ER. Effect of Pattern and Duration of Breastfeeding on the Consumption of Fruits and Vegetables among Preschool Children. PLoS One 2016;11(2):e0148357.

12. Brasil. Ministério da Saúde (MS), Centro Brasileiro de Análise e Planejamento. Pesquisa Nacional de Demografia e Saúde da Criança e da Mulher - PNDS 2006: dimensões do processo reprodutivo e da saúde da criança. Brasília: MS; 2009.

13. World Health Organization (WHO). Indicators for assessing infant and young child feeding practices part 2 : measurement. Washington: WHO; 2010.

14. Instituto Brasileiro de Geografia e Estatística (IBGE). Suplemento de Segurança Alimentar e Nutricional da Pesquisa Nacional de Amostra por Domicílios - PNAD 2013. Rio de Janeiro: IBGE; 2014.

15. Associação Brasileira de Empresas de Pesquisa (ABEP). Critério de Classificação Econômica Brasil. São Paulo: ABEP; 2009.

16. Instituto Brasileiro de Geografia e Estatística (IBGE). Análise do consumo alimentar pessoal no Brasil. Rio de Janeiro: IBGE; 2011

17. Hart CN, Raynor HA, Jelalian E, Drotar D. The association of maternal food intake and infants' and toddlers' food intake. Child Care Health Der 2010;36(3):396-403.
18. Oliveira DA, Castro IR, Jaime PC. Complementary feeding patterns in the first year of life in the city of Rio de Janeiro, Brazil: time trends from 1998 to 2008. Cad Saude Publica 2014;30(8):1755-1764.

19. Rollins NC, Bhandari N, Hajeebhoy N, Horton S, Lutter CK, Martines JC, Piwoz EG, Richter LM, Victora CG. Why invest, and what it will take to improve breastfeeding practices? Lancet 2016;387(10017):491504.

20. Pan American Health Organization (PAHO). Recommendations from a Pan American Health Organization Expert Consultation on the Marketing of Food and Non-Alcoholic Beverages to Children in the Americas. Washington: PAHO; 2011.

21. Millar L, Rowland B, Nichols M, Swinburn B, Bennett $\mathrm{C}$, Skouteris $\mathrm{H}$, Allender S. Relationship between raised BMI and sugar sweetened beverage and high fat food consumption among children. Obesity 2014;22(5):E96-103.

22. Instituto Brasileiro de Geografia e Estatística (IBGE). Antropometria e estado nutricional de crianças, adolescentes e adultos no Brasil. Rio de Janeiro: IBGE; 2010.

23. Fall CH, Borja JB, Osmond C, Richter L, Bhargava SK, Martorell R, Stein AD, Barros FC, Victora CG, COHORTS group. Infant-feeding patterns and cardiovascular risk factors in young adulthood: data from five cohorts in low- and middle-income countries. Int J Epidemiol 2011;40(1):47-62.

24. Weng SF, Redsell SA, Swift JA, Yang M, Glazebrook CP. Systematic review and meta-analyses of risk factors for childhood overweight identifiable during infancy. Arch Dis Child 2012;97(12):1019-1026.

25. Weng SF, Redsell SA, Nathan D, Swift JA, Yang M, Glazebrook C. Estimating overweight risk in childhood from predictors during infancy. Pediatrics 2013;132(2):e414-421.

26. Victora CG, Bahl R, Barros AJD, França GVA, Horton S, Krasevec J, Murch S, Sankar MJ Walker N, Rollins NC. Breastfeeding in the 21st century: epidemiology, mechanisms, and lifelong effect. Lancet 2016;387(10017):475-490.

27. Arimond M, Ruel MT. Dietary diversity is associated with child nutritional status: evidence from 11 demographic and health surveys. J Nutr 2004;134(10):25792585.

28. Moursi MM, Arimond M, Dewey KG, Treche S, Ruel MT, Delpeuch F. Dietary diversity is a good predictor of the micronutrient density of the diet of 6- to 23-month-old children in Madagascar. J Nutr 2008;138(12):2448-2453.

29. Steyn NP, Nel J, Labadarios D, Maunder EM, Kruger HS. Which dietary diversity indicator is best to assess micronutrient adequacy in children 1 to $9 \mathrm{y}$ ? Nutrition 2014;30(1):55-60.

30. Steyn NP, Nel JH, Nantel G, Kennedy G, Labadarios D. Food variety and dietary diversity scores in children: are they good indicators of dietary adequacy? Public Health Nutr 2006;9(5):644-650.

31. Hipgrave DB, Fu X, Zhou H, Jin Y, Wang X, Chang S, Scherpbier RW, Wang Y, Guo S. Poor complementary feeding practices and high anaemia prevalence among infants and young children in rural central and western China. Eur J Clin Nutr 2014;68(8):916-924. 
32. Lande B, Andersen LF, Veierod MB, Baerug A, Johansson L, Trygg KU, Bjørneboe GE. Breast-feeding at 12 months of age and dietary habits among breastfed and non-breast-fed infants. Public Health Nutr 2004;7(4):495-503.

33. Gondolf UH, Tetens I, Michaelsen KF, Trolle E. Dietary habits of partly breast-fed and completely weaned infants at 9 months of age. Public Health Nutr 2012;15(4):578-586.

34. Vitolo MR, Bortolini GA, Dal Bo Campagnolo P, Hoffman DJ. Maternal dietary counseling reduces consumption of energy-dense foods among infants: a randomized controlled trial. J Nutr Educ Behav 2012;44(2):140-147.

35. Khalessi A, Reich SM. A month of breastfeeding associated with greater adherence to pediatric nutrition guidelines. Journal of Reproductive and Infant Psychology 2013;31(3):299-308.

36. Mennella JA, Beauchamp GK. Maternal diet alters the sensory qualities of human milk and the nursling's behavior. Pediatrics 1991;88(4):737-744.

37. Mennella JA, Jagnow CP, Beauchamp GK. Prenatal and postnatal flavor learning by human infants. Pediatrics 2001;107(6):E88.

Artigo apresentado em 06/07/2017

Aprovado em 17/04/2018

Versão final apresentada em 19/04/2018 